\title{
25
}

\section{Communicating Flooding Issues to the Public at Large}

\author{
A. McDonald, A. Mather, and W. Vogelzang
}

The coastal area of KwaZuluNatal is subject to regular flooding, ranging from severe regional flood events such as the 1987 floods when 300 people lost their lives to localised flash floods causing erosion damage. The city of Durban is particularly vulnerable to flood-related problems due to the large urban population and limited amount of developable land. In the past, residential and commercial/industrial development has taken place in flood prone areas placing lives and property at risk. The National Water Act of 1998 states that information relating to floods and potential risks must be made available to the public. The challenge for Durban, with hundreds of kilometres of rivers located in the municipal area, has been to develop a programme to gather flood-related information, identify the parties to whom it should be distributed, and distribute the information in an efficient and appropriate manner. The use of geographical information systems (GIS) has enabled flood studies to be carried out quickly and in a uniform manner, with results beingloaded directly into the Municipality's GIS database. By storing the flood-related information in the GIS environment, it is available to other departments within the Municipality and also the general public via the eThekwini website. The main users of the information in the Municipality are the City Engineering Unit, Disaster Management Department and Development and Planning Department. In addition to the internet, the information is disseminated to the public through direct mailing and word based community Disaster Management Committees. Future developments will include devising better and more efficient ways of informing those living in

McDonald, A., A. Mather and W. Vogelzang. 2004. "Communicating Flooding Issues to the Public at Large." Journal of Water Management Modeling R220-25. doi: 10.14796/JWMM.R220-25.

(C) CHI 2004 www.chijournal.org ISSN: 2292-6062 (Formerly in Innovative Modeling of

Urban Water Systems. ISBN: 0-9683681-9-0) 
informal settlements of the risks they are exposed to and procedures to follow during flood events, active flood warning systems using radar forecasting and empowering community Disaster Management Committees.

\subsection{Introduction}

In 1987 the coastal area of KwaZuluNatal, which includes the port city of Durban, experienced extensive flooding in what is considered to be South Africa's worst natural disaster, when more than 300 people lost their lives and damage exceeding R1,000 million(US\$64 million) occurred (Alexander 2000). More recently, on 13 April 2003, $250 \mathrm{~mm}$ of rain fell in about a $4 \mathrm{~h}$ period in Amanzimtoti, south of Durban, causing severe localised damage (South Coast Sun 2003). A combination of factors contribute to the regular occurrence of flood-related problems in the Durban area:

- topography - steep channels cause erosion damage in the upper catchments and wide flat floodplains result in large inundation areas in the lower reaches;

- densely populated areas, including large informal urban housing areas and commercial/industrial areas in floodplains; and

- rainfall patterns which include high intensity short duration rainfall and heavy regional rainfall events.

Due to the frequency of flood events and the number of people living in the greater Durban area there is a need to raise awareness of the risks people and their properties may be currently living in, and also to inform developers and planners of areas that are unsuitable for development. The issue is particularly critical for those living in informal settlements in the floodplains of rivers. Here, the high population density and temporary housing structures are particularly vulnerable to the effects of flooding.

The National Water Act (Republic of South Africa 1998) emphasises the importance of making information with respect to flood risks available to the public in an appropriate manner and of also limiting future development in unsuitable areas. The onus is on the responsible management institution to provide this information, which in most instances in South Africa is the local authority. The eThekwini Municipality has formalised its approach to gathering, collating and disseminating information on flooding issues. The key steps in this process have been the generation of the data itself, identification of parties for whom the information will be of importance, and devising ways of distributing the information to these parties in an appropriate manner. 


\subsection{The National Water Act}

The eThekwini flood management programme has also coincided with the new requirements of the National Water Act (Act No 36 of 1998) which states that certain information relating to floods and potential risks must be made available to the public, this includes the requirement that the $100 \mathrm{y}$ floodline be demarcated on plans for new township developments. In addition to the requirements of the National Water Act, the eThekwini City Engineering Unit requires that all new developments, or extensions to existing properties, provide information relating to the $50 \mathrm{y}$ and $100 \mathrm{y}$ flood. This requirement has been in place for some years, and has simply been updated recently to reflect the need to identify the $100 \mathrm{y}$ floodline as stipulated in the Water Act.

The purpose of the Water Act is primarily one of providing information regarding flooding risks, whilst the City Engineering Unit requirements also relate to the control of development within the $50 \mathrm{y}$ floodplain. If a proposed development is shown to be within the 50 y floodplain, then it must be demonstrated that the foundations are capable of withstanding the forces associated with the flood event, and also that the development itself will not affect the flood levels on adjacent properties.

In both cases of the Water Act and the City Engineering Unit requirements noted above, information regarding flooding is required for future developments. The Water Act, however, goes on to state that:

"a water management institution must, at its own expense, make information at its disposal available to the public in an appropriate manner, in respect of

(a) a flood which has occurred or is likely to occur;

(b) a drought which has occurred or is likely to occur;

(c) a waterwork which might fail or has failed, if the failure might endanger life or property;

(d) any risk posed by any dam;

(e) levels likely to be reached by floodwaters from time to time;

(f) any risk posed by the quality of any water to life, health or property; and,

(g) any matter connected with water or water resources which the public needs to know."

This therefore also identifies the need to provide flood-related information for existing developed areas. Within this broad list, it is therefore clear that the responsibility for determining what information is made available is very much left to the water management institution. The onus should obviously be on transparency, and providing as much information as is reasonable without 
causing undue alarm. The demarcation of the $100 \mathrm{y}$ floodline is the preferred method of making people aware of the possibility of inundation of existing properties, whilst the $50 \mathrm{y}$ floodline is good for use as a development control line (Alexander, 2000). By making the $100 \mathrm{y}$ floodline for streams and rivers with a catchment area greater than $1 \mathrm{~km}^{2}$ available to the public, the City Engineering Unit is fulfilling an important component of the National Water Act.

\subsection{The eThekwini Municipal Area (eMA)}

The eThekwini Municipal Area (eMA), which comprises the port city of Durban and outlying suburbs, is typified by diverse land use, with only $35 \%$ of the $2297 \mathrm{~km}^{2}$ area being predominantly urban in character. Over $80 \%$ of the 2.8 million population lives in these areas, many in dense informal housing (eThekwini Municipality 2003). The eMA is characterised by diverse topography, from steep escarpments in the west to a relatively flat coastal plain in the east. This topography has created a dense network of natural drainage paths that feed a number of major regional rivers, including the Mgeni and Mlazi Rivers, as well as several smaller rivers, including the Mhlangane, Palmiet, Umbilo, Mhlatuzana, and Mbokodweni. In each case, the catchment areas of these smaller rivers fall almost entirely within the eMA boundary, and their landuse is characterised by rural/agricultural areas in the headwaters, residential areas in the middle portion and industrial/commercial areas in the flat coastal plain.

The steep topography means that developable land is at a premium, and in the past, developers have squeezed as much land area as possible out of a given plot, and this has frequently meant encroaching into the natural floodplain of the water courses. The rivers that flow through the residential areas on their way to the flatter coastal strip do not have large overbank areas with wide floodplains, and people are generally unaware that the babbling brook at the far end of their garden, which is no more than a trickle for much of the year, can rise rapidly towards their back door during heavy rainfall events. In February and December of 1999, severe damage was caused in the Pinetown and Westville areas of Durban, not through extensive inundation of large areas, but primarily as a result of the erosion of banks and retaining walls by the fast flowing water. In several instances, flooding was exacerbated by blockages at road bridges and culverts. Much of the debris was vegetation - trees, branches and garden refuse (Arcus Gibb, 2000). 


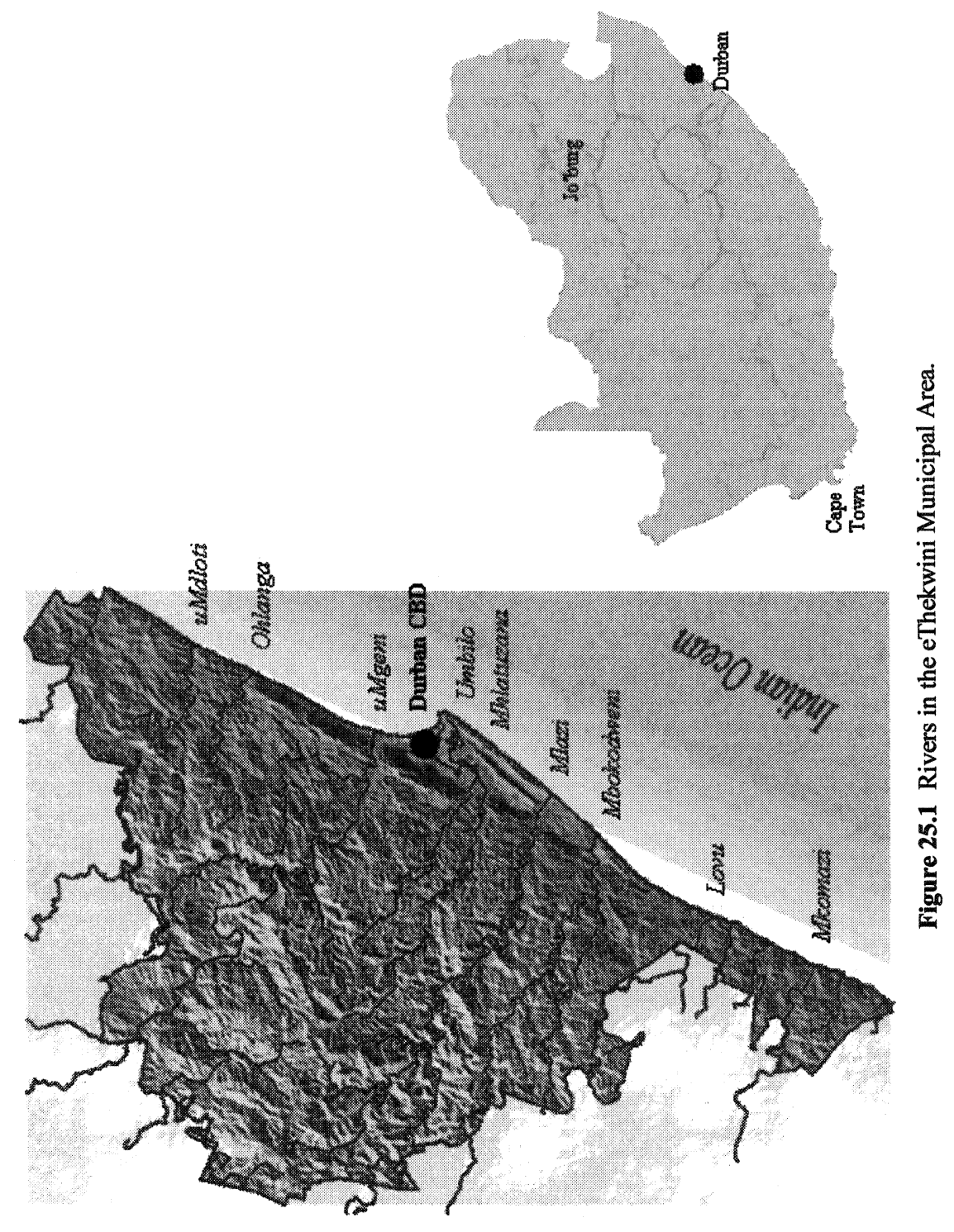


This event was declared a national disaster after 20 people lost their lives. Over 3000 people in the Metro were assisted by the Disaster Management Department with about 200 formal properties flooded and 400 informal houses destroyed by the floods. Eighteen roads were extensively damaged, nine cars washed away by floods and 38 major landslides occurred. Damage to the council infrastructure was approximately R15 million (US\$96 million) with damage to private properties being considerably higher.

Figure 25.2 shows a typical flooding scene in the middle section of the Mhlatuzana River catchment, where the well-defined channels and steep longitudinal profile result in high velocity flow.

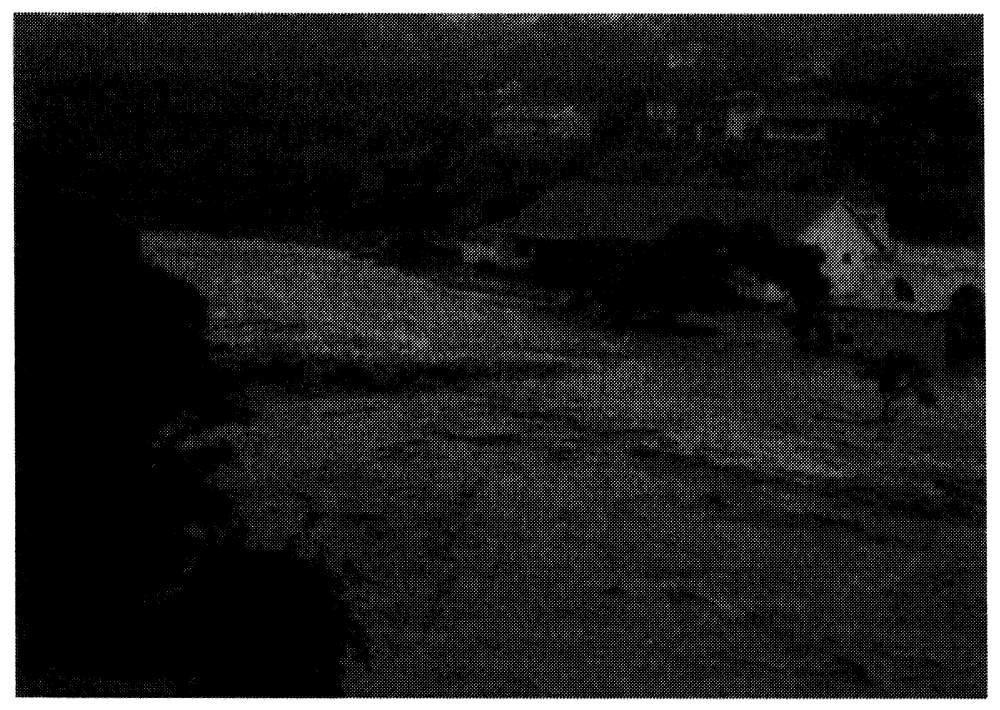

Figure 25.2 Flooding in the middle catchment.

The lower $2 \mathrm{~km}$ or so of the Durban rivers pass through the flat coastal plains before entering the Indian Ocean. Before the development of Durban around the Bay of Natal, the rivers fed a natural lagoon system along this narrow coastal strip. As development took place, first of the harbour and central business district (CBD), and then later the industrial/commercial areas of Prospecton and Bayhead, so the rivers were diverted and/or canalised.

In most instances, the canal structures have proved inadequate to convey the runoff from severe storm events, with overtopping and inundation of large areas taking place far more frequently than the design return period predicted. This therefore places large areas of commercial and industrial areas, including 
nationally important industries such as SAPREF (South African Petroleum Refineries), at greater risk of flooding than was originally thought. During the 1987 floods, the SAPREF plant was out of commission for several days at undeclared millions of Rands loss of income and disruption of fuel to the economy.

Figure 25.3 shows inundation of the Mondi Paper Mill (left hand side) and SAPREF (right hand side) plants that took place during the 1987 floods as a result of overtopping of the Mlazi Canal.

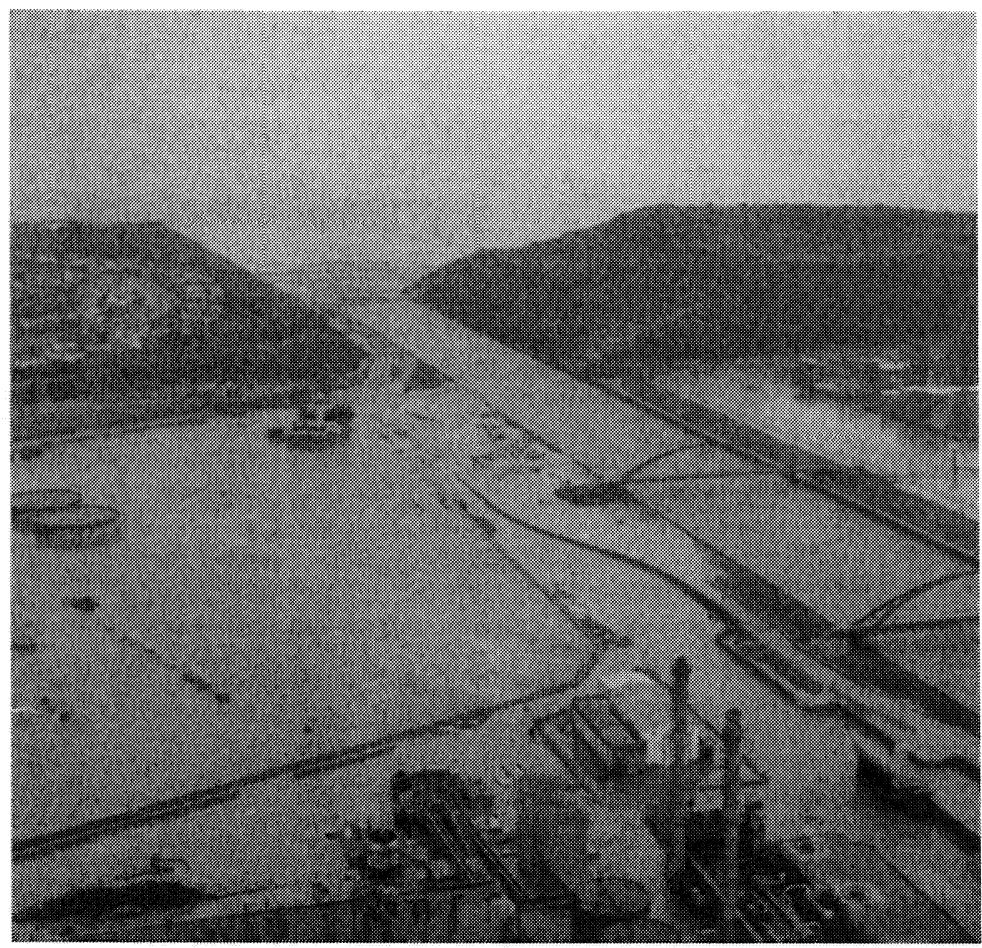

Figure 25.3 Flooding in the lower catchment.

These two cases illustrate the nature of the flooding problems in the eMA. Years of development have produced a growing conflict between the needs of the built-up urban environment and the use of the natural rivers as the main drainage routes. To ease some of the problems relating to this conflict a holistic catchment management approach is needed, and one of the first steps in this process is the gathering of background and baseline data. Hence the Drainage and Coastal Engineering Department of the eThekwini City EngineeringUnithas 
over the past five years been generating a database of flood-related information for the purposes of disaster management, development planning and maintenance management. This type of information is related more to the 'harder' engineering issues of catchment management, as opposed to 'softer' socioeconomic and environmental issues. Floodlines are only one output from the Durban rivers flood studies. Other outputs include the identification of flow velocities, depths, erosion potential, bridge and culvert capacities and floodplain storage areas.

\subsection{The Use of GIS in Flood Studies}

The use of geographic information systems (GIS) in hydrological modeling is not new. The spatial and analytical capabilities of GIS as well as the availability of more raw data in this format make it the ideal tool to assist the engineer in catchment modeling and flood routing. The US Army Corp of Engineers' (USACE) Hydrologic Engineering Center (HEC) has been particularly active in using the functionality of GIS in the development of its next generation of hydrological and hydraulic software.

The HEC's original suite of software, which included HEC-1 (catchment runoffmodeling) and HEC-2 (steady flow river analysis), were popular and well used by engineers all over the world. The updated Windows versions (HECHMS replacing HEC-1 and HEC-RAS replacing HEC-2) of these programs provided graphical user interfaces, and consequently easier data entry and better results output. The recent versions of these programs have taken these aspects of the modeling process a step further through the development of GIS pre- and post processors. These comprise the Arcview extensions, HECGeoHMS and HEC-GeoRAS.

The HEC suite of programs, including the GIS extensions, have been successfully used in the generation of floodlines for the Drainage and Coastal Engineering Department at eThekwini Municipality. Several major advantages have been evident in carrying out the work in this manner, including:

- uniformity of the input data - the same GIS datasets (soils, landuse, contours) are used for each catchment model and river model;

- faster preparation of input to the catchment and river models, and quicker generation of results in GIS format;

- uniformity of results - the automated process removes a certain amount of subjectivity; 
- improved quality of results presentation, and ready for direct loading onto the Municipal GIS database; and

- updating the catchment and hydraulic models when new calibration information is available is quick, as is the re-production of flood inundation maps.

The improvements stem largely from the speed with which the GIS can extract relevant spatial data, and the fact that the pre-processors automatically create input files to the HEC-HMS and HEC-RAS programs in the correct format. Once the hydraulic modeling is complete in the HEC-RAS package, the reverse process takes place, with export files being generated automatically for conversion into shapefiles depicting flood inundation areas.

This automation does not imply that subjective judgements from the modeler are no longer required. There are still critical areas where the modeler must be aware of potential errors in the input data, or in the results. These important checks have been incorporated into the modeling process, which is shown diagrammatically in Figures 25.4-25.6.

The GIS methodology is described in detail in the manuals that accompany the Arcview extension programs (USACE, April 2000 and July 2000), and its particular use for the Durban studies in Hansen, Kitching and McDonald (September 2001). The basic procedure involves setting up a catchment model from which peak discharge values are determined at intervals along the river length. These peak discharges are then used as input to the river model to determine water levels. Under the catchment modeling procedure a basin file is created using a digital elevation model (DEM) and the HEC-GeoHMS preprocessor in GIS. Once the basin file is created and imported into HEC-HMS, the meteorological data (rainfall hyetographs) for different design flood events is added manually. The SCS Unit Hydrograph (SCS-UH) method has proved to be the most appropriate technique for the Durban catchments. The hydraulic modeling process involves creating a geometric representation of the river channel system. This geometry file is created for input into the HEC-RAS modeling program using a triangular irregular network (TIN) derived from a $2 \mathrm{~m}$ digital contour set and the HEC-GeoRAS pre-processor. Once the geometry file is created and imported into HEC-RAS, the peak discharge data produced by HEC-HMS is input manually. The results from the HEC-RAS modeling (which include flood levels, velocity, depths, etc) are written to an export file. This file is then sent back to the GIS environment, where it is run through the HEC-GeoRAS extension, which now functions as a post-processor. Here the water level results are combined with the TIN to automatically create a floodline shapefile. Further processing is then carried out to convert 


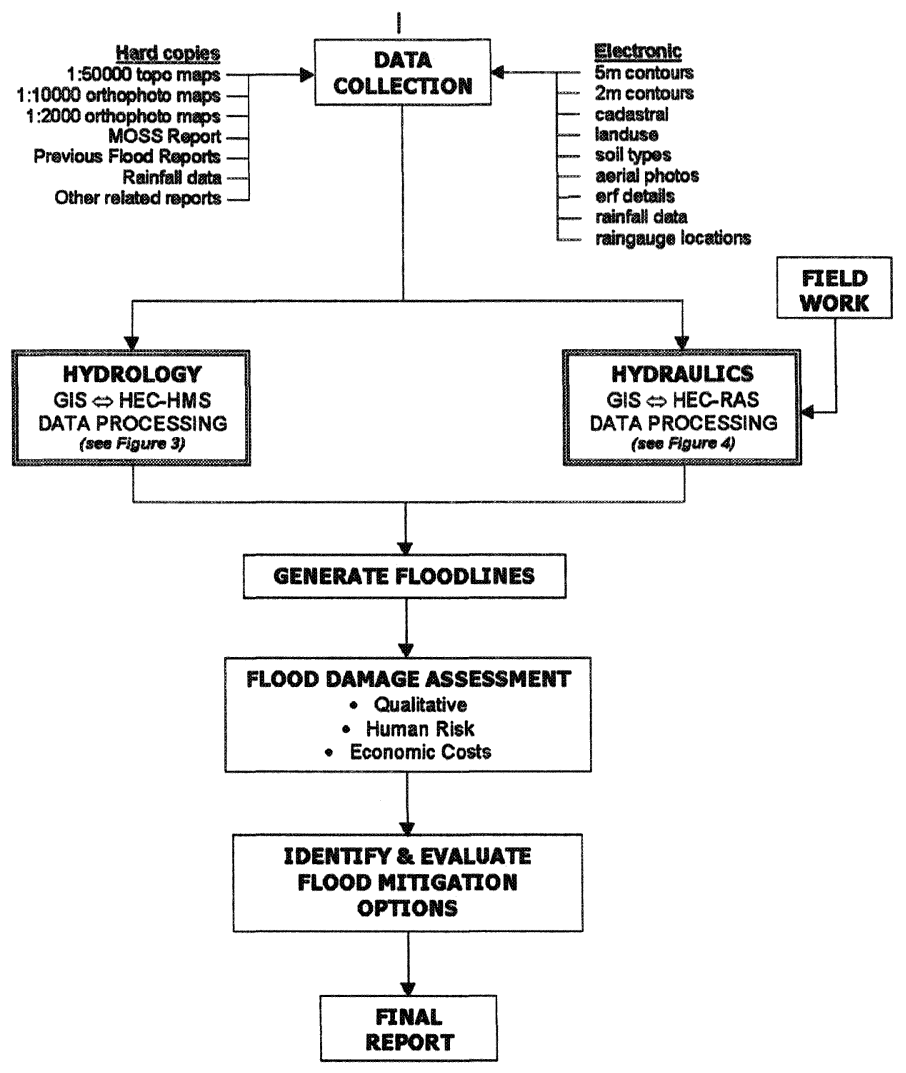

Figure 25.4 Floodline study methodology.

the velocity and depth data into 'contour' themes which show how the depth and velocity varies within the demarcated floodline. Once this basic flooding information is in the GIS database, additional information such as photographs and structure data is entered.

The fourth point noted in the list of advantages above is of particular relevance when considering the main purpose of actually producing floodline information in the first place - that of informing the public at large of flood risks. The other important reasons include the use of such information by the Drainage and Coastal Engineering Department to assess infrastructure and maintenance requirements relating to flooding problems and by the development 


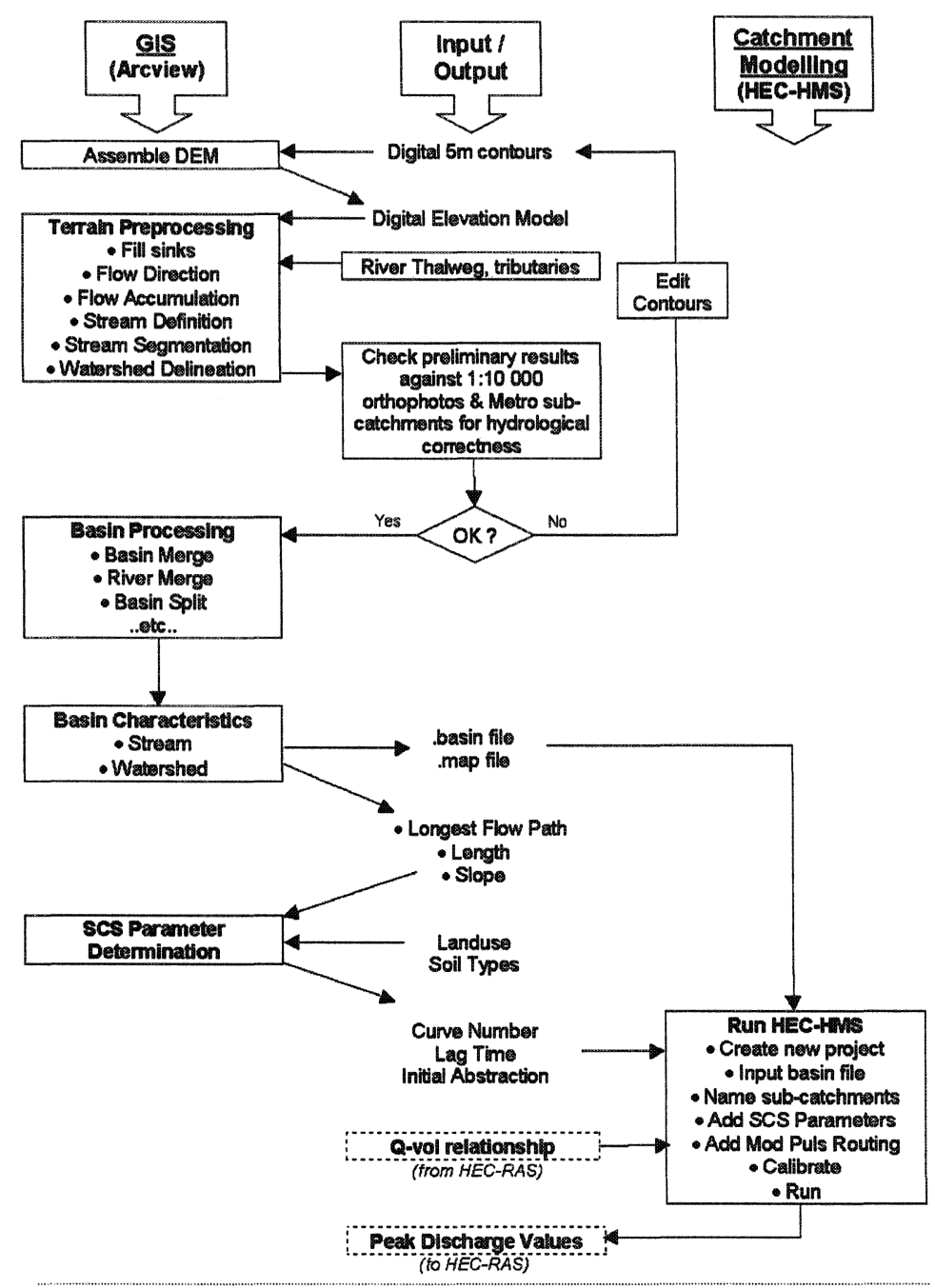

Figure 25.5 Catchment modeling : GIS - HEC-HMS processing.

and planning sections of other Municipal Departments. The key issue in each of these cases is making data readily available in formats the end-user is happy with. Whilst not providing all the answers, a GIS database in conjunction with several other integrated information channels goes a long way to providing this need. 


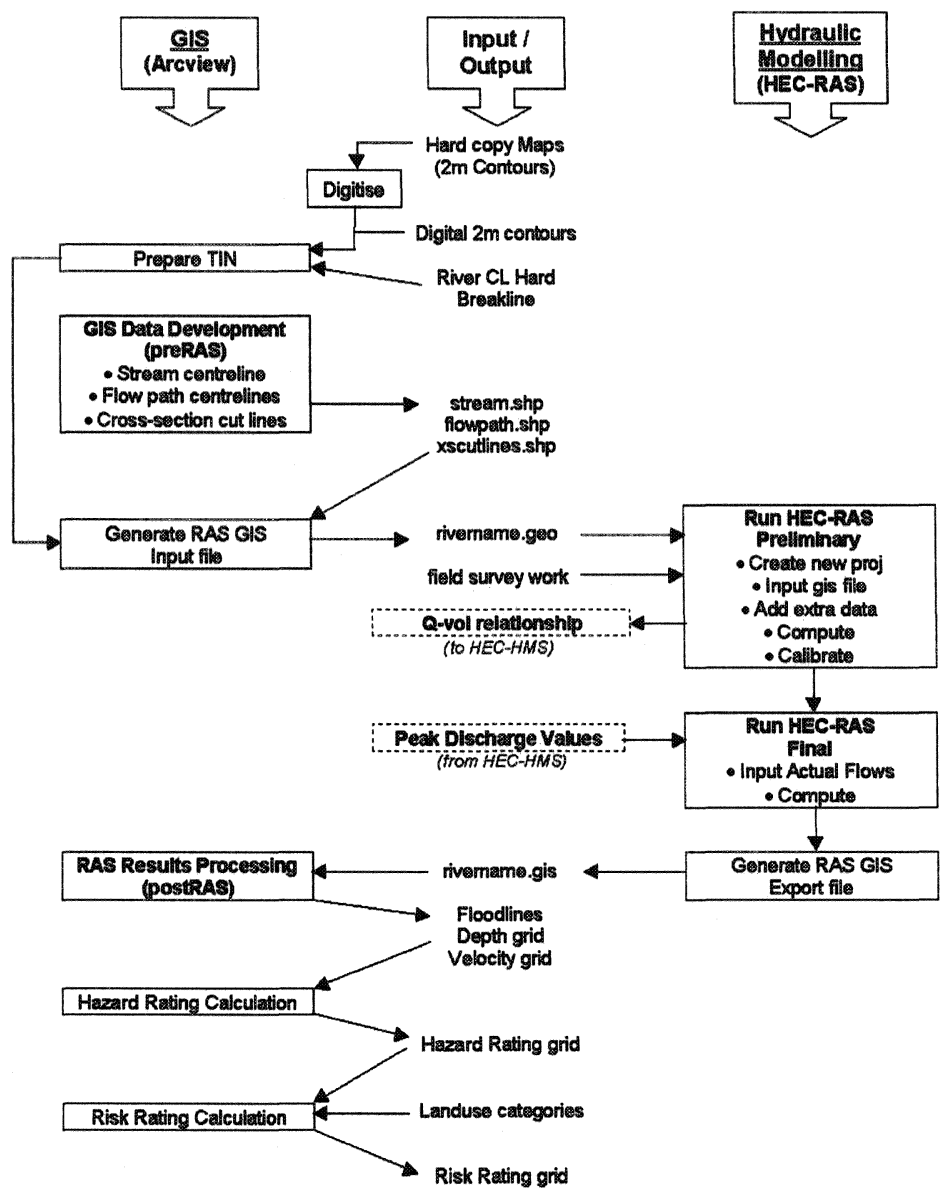

Figure 25.6 Hydraulic modeling: GIS - HEC-RAS processing.

\subsection{Using the Floodline Information}

During the course of catchment and hydraulic modeling many results are produced. An important process in floodline studies methodology is therefore the filtering, interpretation and re-processing of raw results to produce meaningful information for the end-user - in this case, the Drainage and Coastal Engineering Department. When passing the information on to further users, such as the public, via the web-based GIS map on the eThekwini internet site, further filtering of the information is carried out by the Department. 
The users of the information can thus be divided into two main groups:

- eThekwini Municipality, and

- the public,

each of which can be further subdivided as discussed below.

\subsection{1 eThekwini Municipality}

\section{Drainage and Coastal Engineering Department}

Output from the GIS-based floodline studies undertaken for the Durban City Engineering Unit department comprise a GIS dataset, a hardcopy map book and a hardcopy report. The hard copies basically replicate what is in the GIS data.

The information provided includes:

- $100 y$ floodline maps and shapefiles,

- $20 \mathrm{yr}$ and $50 \mathrm{yr}$ floodline shapefiles,

- flood depth grids,

- flow velocity grids,

- bridge and culvert hydraulic data,

- catchment data,

- peak Discharge data,

- cross-section plots,

- qualitative descriptions of flood-prone areas, and

- possible mitigation measures (including cost-benefit analysis where appropriate).

This information is used by the Drainage and Coastal Engineering Department in a number of areas. The first is the use of the $100 \mathrm{y}$ floodline together with cadastral information to identify properties owners who lie within the $100 \mathrm{y}$ floodplain. Once identified, the property owners are sent a standard letter informing them of the risk of flooding.

To date approximately 7,000 letters have been sent to residents affected by flooding from the 1:100 y flood. Out of these approximately 2,000 dwellings / commercial properties have the 1:100 y flood level higher than the floor level!

Informal settlements subject to flooding have been identified in the flood studies, and have been prioritised by the Metro Housing Department for early relocation in terms of their $15 \mathrm{y}$ housing and slums clearance programme.

One of the main uses of the information is to identify and prioritise capital works to help mitigate flooding problems. The interpretation and re-processing of the raw HEC-RAS results is important here. An example is the identification of the extent to which culvert and bridge structures create backwater effects and commensurate flooding problems for properties on the upstream side. 
Figure 25.7 shows typical data for such a situation. Here, a photograph of the bridge is provided together with information regarding the backwater effects. In this instance, the culvert is under a large embankment, and a significant headwater depth is required to convey the high flood discharges through the culvert. Unfortunately, a number of residential properties are located just upstream of the culvert and are therefore subject to inundation by several metres.

This therefore demonstrates one of the ways that the database capabilities of the GIS can add value to the basic floodline information.

In many instances, the nature of the flooding problem, together with the high capital costs, means that structural flood protection measures such as canalisation, levees or detention ponds are not appropriate. The reduction of flood-related problems, including the risk of loss of life, is therefore best handled through effective emergency planning.

\section{eThekwini Disaster Management}

The Disaster Management Department are interested in flood-related information for purposes of planning and management both before, during and after a flood event.

In terms of pre-flood planning, the department makes use of the spatial analysis tools in GIS to identify issues such as areas where the risk of loss of life is greatest, numbers of people affected, disruption of transport routes and reaction strategies. In this instance, having the flood information in a GIS database along with other relevant spatial data makes the planning process easier and more effective.

Another major concern is the education of people with regard to the risks of flooding in their area. This is particularly relevant in the informal residential areas which are at risk during less severe events than the more formal areas.

Disaster Management Department has established a Disaster Management Volunteers program aimed at preparing communities to deal with situations of disaster including flooding. The community Disaster Management Committees are word based with the Ward Councillor included in the committee.

The project was conceptualised to create capacity to cope with disasters and emergencies at grassroots level.

This is primarily aimed at informal settlements and since 1996, 800 volunteers have been trained across 25 of the 100 Wards.

Related to the passive flood awareness programme is the concept of an active early warning system. Research is currently underway into the use of radar-forecasting to predict rainfall patterns which are then routed through a 


\section{Ref. No.}

Description

Opening Size

Overtopping Capacity $\left(\mathrm{m}^{3} / \mathrm{s}\right)$

Corresponding Return Period

Overtopping depth (m)

yr flood

$50 y r$ flood

Jmb-1B-21934

Box Culvert
of $3.7 \times 4.0 \mathrm{~m}$ Barrels

100yr flood

Backwater Effects:

$\begin{array}{lcc} & \text { Length }(\mathrm{m}) & \text { Depth }(\mathrm{m}) \\ \text { 20yr flood } & 275 & 1.8 \\ 50 \mathrm{yr} \text { flood } & 430 & 3.4 \\ \text { 100yr flood } & 430 & 3.4\end{array}$

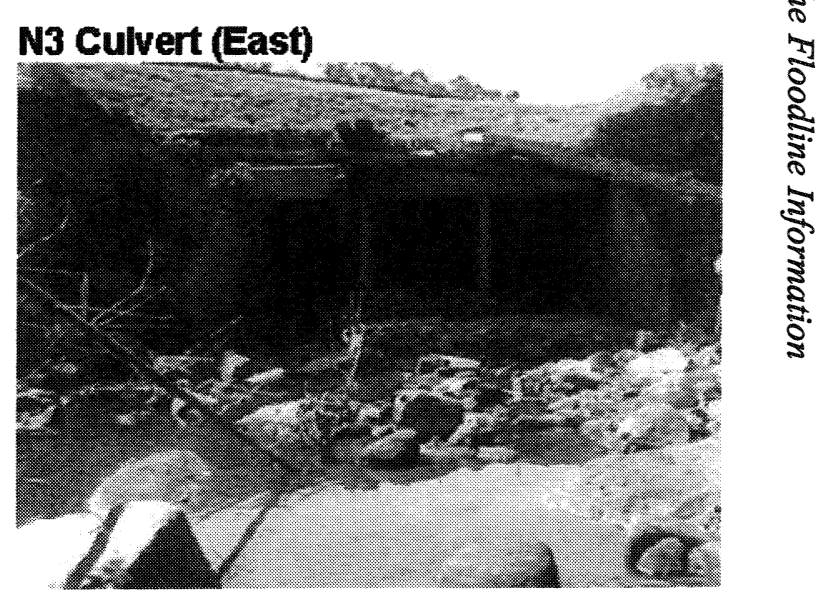

Figure 25.7 Culvert hydraulic data. 
catchment model to predict peak discharge values (Pegram and Sinclair, January 2002). In its simplest form, these peak discharge values are then used to select a flood inundation map from a library of GIS shapefiles, created previously for a range of flood conditions. Due to the relatively small catchments and steep topography in the eMA, the warning system would give only a few hours warning at best, although even this short period can prove beneficial in reducing loss of life. As advances in the radar forecasting progress, so the warning time period will no doubt increase.

\section{Other Municipal Departments}

Other Municipal Departments such as Water, Wastewater, Development Planning, Environmental, etc, have access to the $100 \mathrm{y}$ floodline information via the internal GIS database. Should more detail be required, such as the $20 \mathrm{y}$ or $50 \mathrm{y}$ floodlines, or flow velocity information, then a request is made to the Drainage and Coastal Engineering Department.

\subsubsection{The Public at Large}

In the context of this chapter, the 'public at large' refers to a range of parties external to the eMA and other government institutions. These include:

- property owners,

- residential (formal and informal),

- industrial,

- commercial,

- service providers,

- planners,

- engineers,

- architects,

- environmental scientists,

- social scientists,

- estate agents,

- insurance companies, and

- research groups.

Information regarding flooding is currently disseminated to the general public in a number of ways. The first is through the delivery of a letter directly to those property owners affected by the $100 \mathrm{y}$ floodline as described in Section 25.3. The second is through the hard copy flood map books which are made available for viewing at the City Engineer's Department. The third is through the internet. 
The 'eThekwini Online' website (www.durban.gov.za) provides information on the Metro area to the visitor, resident and business community at various levels (Figure 25.8).

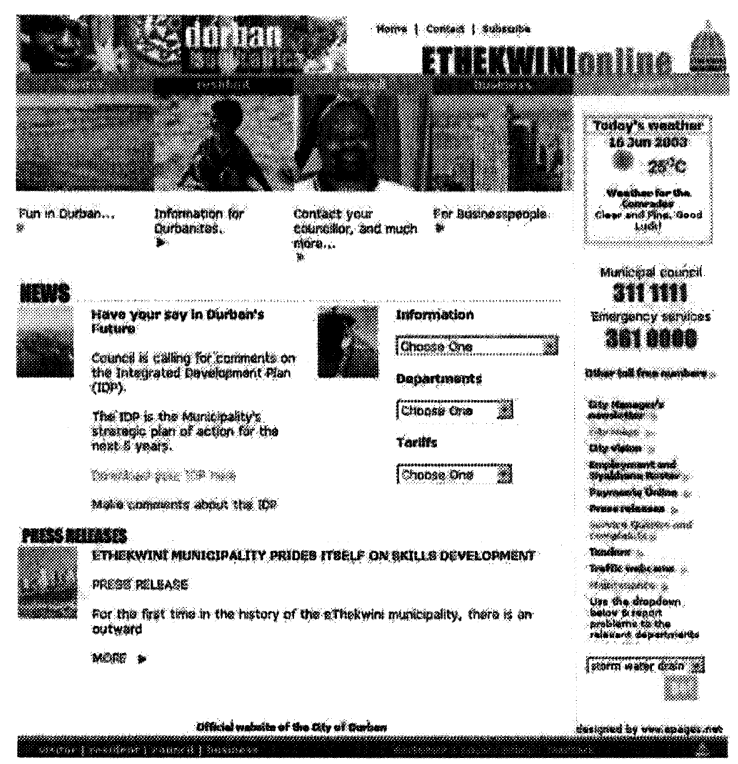

Figure 25.8 eThekwini online website.

For the resident it provides a portal through which problems and queries regarding a range of municipal services are directed to the relevant department for handling. In this mode, the website is acting as an alternative means of communication for people to make contact regarding a problem (in addition to the telephone and in writing).

However, the website now incorporates means by which the Municipality can convey information on services directly to residents. This has been accomplished through the use of Web GIS technology, which allows the internet user to access directly the eThekwini GIS database. A list of the data that is available for viewing is provided in Table 25.1.

A view showing the $100 \mathrm{y}$ flood line layer together with street addresses is shown in Figure 25.9.

Residents and potential developers are therefore able to check the extent to which their property is likely to be affected by flooding. Having viewed information, whether it be floodlines, or other municipal services, they are then able to submit specific queries or raise issues via a dropdown menu. The 
Table 25.1 eThekwini on-line GIS database layers.

\begin{tabular}{lll}
\hline Unicity Boundary & Cadastral & Storm Water \\
Metro Boundary & Pressure Reducing Valves & Pipes \\
Unstable Soils & Fittings & WWTW \\
Landmarks & Watermains & Sewer \\
100yr Flood Plains & Roads & Pumpstation \\
DMOSS & Road Outline & Sewer_Manholes \\
Addresses & 5m Contours & Sewer Pipes \\
Beacons & Culvert Centroid & Dwellings \\
Parcelsides & Culverts Line & Wards \\
Properties & Storm Water & Zoning \\
Proposed & Manholes & Black \& White Aerial Photo \\
\hline
\end{tabular}

dropdown menu gives a list of categories such as roads, stormwater, water, sewerage, etc from which the person can choose. The queries are then routed directly to the relevant department.

When making a telephonic enquiry, residents can either phone the relevant department's enquiry line or the customer service number, from where it is routed to the relevant department.

The two-way information flow is presented schematically in Figure 25.10.

\subsection{Future Developments}

"Hard" engineering issues are dealt with relatively easily today with new technology. The challenge is to integrate the "soft" socio-economic and environmental issues with the hard. A number of initiatives are presently being undertaken to bridge this gap, including:

- Extension of floodline studies into catchment planning and management studies. Current pilot in progress in the Ohlanga River.

- Roll out of over 20 customer contact centres where in addition to paying for water, rates, etc customers can report problems and obtain information via the GIS databases.

- Roll out internet access points to municipal libraries.

- Roll out Disaster Management Volunteer Programme to all 100 Wards in the eThekwini Municipality with its focus on rural and 


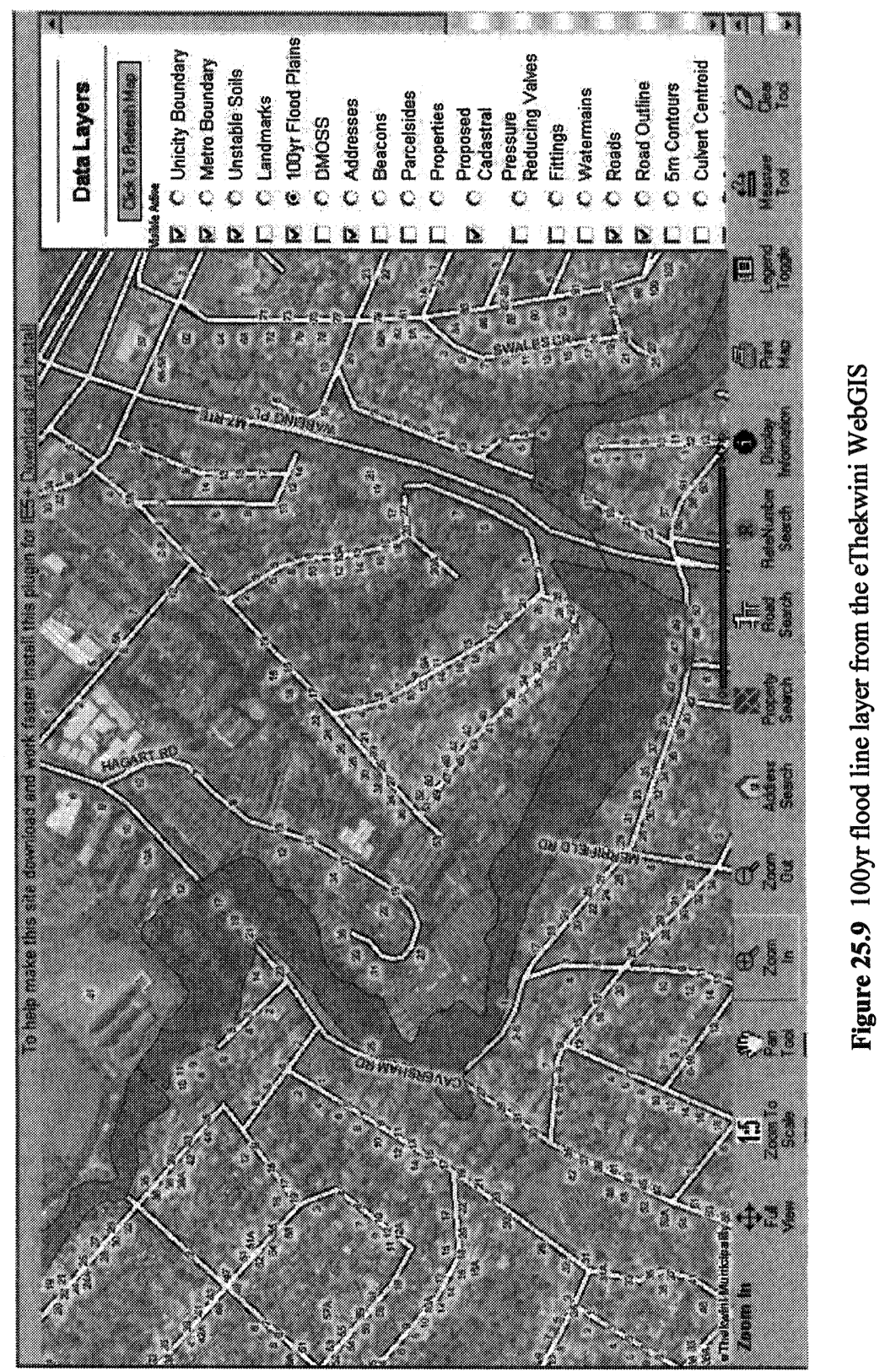




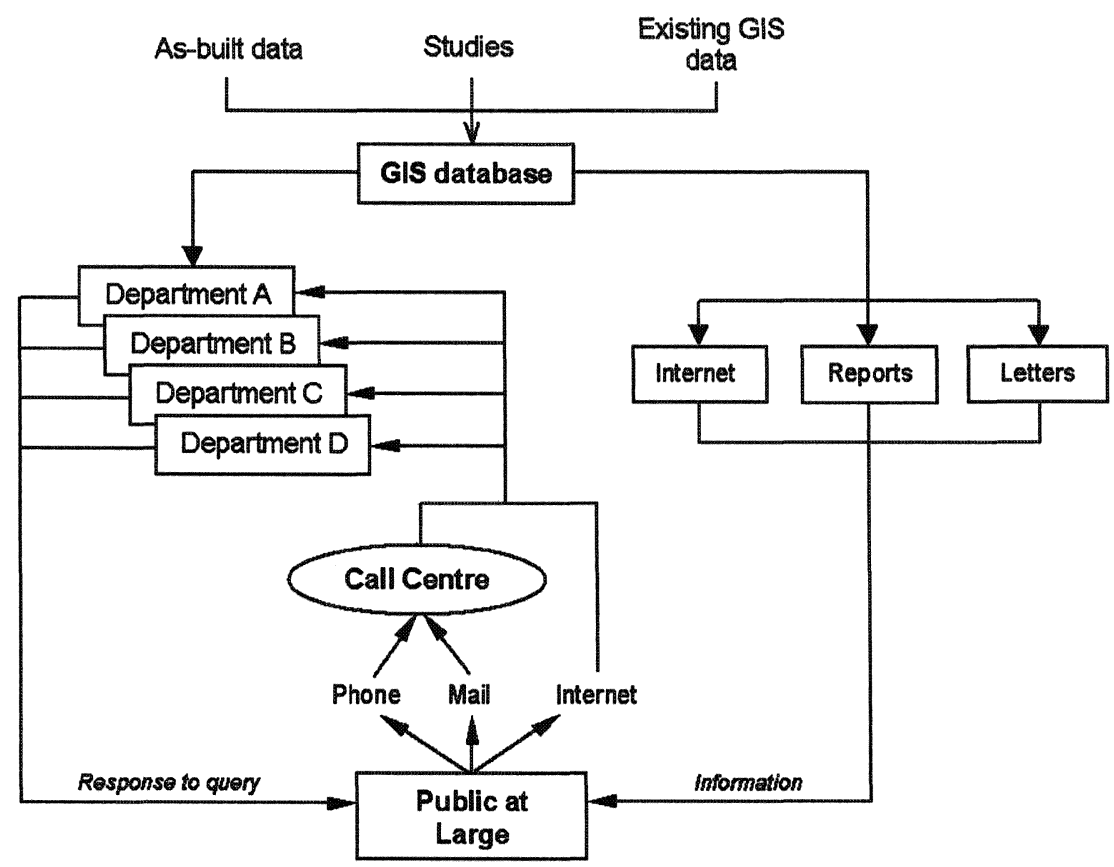

Figure 25.10 Information flow between eThekwini municipality and the public.

peri-urban communities. Use this community structure to alert communities of flooding hazards and what actions they can take to minimise this.

- Continue to improve the early flood warning system.

- Link into catchment management fora.

- Strengthen ties with the Catchment Management Agency.

\section{References}

Alexander (April 2000). Flood Risk Reduction Measures.

Arcus Gibb (November 2000). Umbilo River Floodline Study. Report prepared for Durban City Engineer 
eThekwini Municipality (June 2003). Integrated Development Plan 2003-2007. Hansen, Kitching, McDonald (September 2001). GIS Applications in Flood Line Studies. Paper presented at the GIMS User Conference, Johannesburg 2001.

Pegram \& Sinclair (January 2002). A Linear Catchment Model for Real Time Flood Forecasting. WRC Report No. 1005/1/02.

Republic of South Africa (August 1998). National Water Act, Act No. 36 of 1998, Chapter 14, Part 3

South Coast Sun (April 2003). Newspaper article of 18 April 2003.

US Army Corps of Engineers (April 2000). HEC-GeoRAS User's Manual.

US Army Corps of Engineers (July 2000). HEC-GeoHMS User's Manual. 